\title{
Investigating Daily Naira/Dollar Exchange Rate Volatility: A Modeling using GARCH and Asymmetric Models
}

\author{
Yakubu Musa* and Bello Abubakar** \\ *Department of Mathematics (Statistics Unit), Usmanu Danfodiyo University, Sokoto, Nigeria \\ **Department of Mathematics, Gombe State University, Nigeria
}

\begin{abstract}
Exchange rates are important financial problem that is receiving attention globally. This study investigated the volatility of daily Dollar/Naira exchange rate using $\operatorname{GARCH}(1,1), \operatorname{GJR}-\operatorname{GARCH}(1,1)$, TGARCH $(1,1)$ and TS-GARCH $(1,1)$ models by using daily data over the period June $1^{\text {st }}, 2000$ to July 26, 2011 consisting of 4083 observations. The results from all the models show that volatility was persistent (i.e. exceed 1) indicating $\operatorname{GARCH}(1,1), \operatorname{GJR}-\operatorname{GARCH}(1,1)$, and $\operatorname{TS}-\operatorname{GARCH}(1,1)$ models variances are not stationary but for TGARCH $(1,1)$ model (i.e. below 1) indicating the variance is stationary. The GJR-GARCH $(1,1)$ and TGARCH $(1,1)$ models show the existence of statistically significant asymmetry effect. The results from all the asymmetry models rejected the hypothesis of leverage effect. The TGARCH $(1,1)$ and TS-GARCH $(1,1)$ models are found to be the best models, they have all the parameters of the variance being significant and with lower information criteria.
\end{abstract}

Keywords: Volatility, GARCH, Exchange rate, Nigeria

\section{Introduction}

Exchange rates of currencies are important financial problem that have received a great deal of interest from statisticians, actuaries and financial economists. The collapse of the Breton-Woods arrangement coming out of the 1973 world crisis gave way to a period of floating exchange rates throughout the developed and the third worlds [12]. Since then, the volatility modeling and forecasting in spot foreign exchange rates have attracted much attention and fostered a growing body of theoretical and empirical works to investigate the behavior of currency movements. In Nigeria, like most developing countries, volatility modeling and forecasting have attracted little attention for the simple reason that the foreign exchange market and the capital market are largely undeveloped[15]. The foreign exchange market in the fixed exchange rate period was characterized by high demand for foreign exchange which cannot be adequately met with the supply of foreign exchange by the Central Bank of Nigeria (CBN). The fixed exchange rate period was also characterized by sharp practices perpetrated by dealers and end-users of foreign exchange [29]. The understanding of the behavior of exchange rate behavior is important to monetary policy [28]. The exchange rate has been found to be an important element in the monetary transmission process[27] and a movement in this price has a significant pass-through to consumer prices. The uncertainty of the exchange rate shows how much economic behaviors are not able to perceive the directionality of the actual or future volatility of exchange rate, that is, it is a different concept from the volatility of the exchange rate itself in that it means that the more forecast errors of economic behaviors made, the higher the trends in the uncertainty of the exchange rate are shown [33]. Researchers have introduced various models to explain and predict these patterns in volatility. [8] introduced the autoregressive conditional heteroskedasticity $(\mathrm{ARCH})$ to model volatility. [8] modeled the heteroskedasticity by relating the conditional variance of the disturbance term to the linear combination of the squared disturbances in the recent past. [4] generalized the $\mathrm{ARCH}$ model by modeling the conditional variance to depend on its lagged values as well as squared lagged values of disturbance, which is called generalized autoregressive conditional heteroskedasticity (GARCH). Since the work of [8] and [4], various variants of GARCH model have been developed to model volatility. Some of the models include IGARCH originally proposed by [10], GARCH in- Mean (GARCH-M) model introduced by [11], the EGARCH or Exponential GARCH model proposed by [25], TARCH or Threshold ARCH and Threshold GARCH were introduced independently by [34] and [14], the Power ARCH model generalized by [6].

Volatility modeling of exchange rate has many practical applications in statistics, economics and finance. [16] used 10 years (1974 - 1983) of daily closing-bid prices, consisting of 2,510 observations, for five countries in comparison of US dollar to estimate the autoregressive conditionally heteroscedastic (ARCH) and generalized autoregressive conditionally heteroscedastic $(\mathrm{GARCH})$ models along with the other modified/altered types of ARCH and GARCH. The findings of [16] proved that the two under study models were capable of removing all heteroscedasticity in price changes. It was also concluded that the standardized residuals from all the ARCH and GARCH models using the standard normal density were highly leptokurtic, 
and the standard GARCH $(1,1)$ and $\mathrm{EGACH}(1,1)$ were found to be more efficient for removing conditional heteroscedasticity from daily exchange rate movements.

Some other studies on the volatility of exchange rates include [23], [22], and [33] among others. [24] modeled the NOK/US Dollar exchange rate through ARCH and GARCH models, the results of which supported that three out of four analyzed series fitted better through GARCH than the ARCH model.

[17] applied the parametric and non-parametric techniques on daily exchange rate of Pak Rupee / US Dollar exchange rate and tried to measure the success of intervention in foreign exchange market in Pakistan, which was done either in shape of alteration in the exchange rate level or smoothing the exchange rate fluctuations. The GARCH results, as reported by [17] proved that intervention was successfully altered, in both direction of exchange rate and smoothed the fluctuations in exchange rate while the event study confirmed that the intervention was successful for level and volatility of the exchange rate.

[26] used a number of GARCH models to investigate the volatility of Naira/US Dollar exchange rate in which the hypothesis of leverage effect was rejected by all asymmetry models, though all the coefficients of the variance equations were significant, the TS-GARCH and APARCH models proved to be the best models.

[19] investigates the effects of interest and exchange rate changes on Turkish bank's stock returns and finds significant negative impact. Their results further indicate that interest and exchange-rate volatility are the major determinants of conditional bank stock return volatility. [2] examined the volatility of Naira/US Dollar and Naira/UK Pound Sterling exchange rates in Nigeria using GARCH model. The data on the monthly exchange rates were collected from Central Bank of Nigeria which spanned through the period 2007-2010. Investigation conducted on the exchange rates showed that volatility on the returns is persistent. The result of normality test indicated that the series residuals are asymmetric. The plots on the original series and unit root test on the return series established the nonstationarity status of Nigerian foreign exchange series.

[1] applied variants of GARCH models under non-normal innovations-t-distribution and Generalized Error Distribution (GED) on selected Nigeria exchange rates. The Berndt, Hall, Hall, Hausman (BHHH) numerical derivatives applied in the estimation of models converged faster and the time varied significantly across models. Asymmetric GARCH model with t-distribution (GARCH-t) was selected in most of the cases whereas for Nigeria-US Dollar exchange rate, GARCH-GED was specified. Both distributions showed evidence of leptokurticity in Naira exchange rate return series.

The exchange rate volatility has implications for many issues in the arena of finance and economics. Such issues include impact of foreign exchange rate volatility on derivative pricing, global trade patterns, countries balance of payments position, government policy making decisions and international capital budgeting. The objective of this paper is to modeled daily Naira/US dollar exchange rate using GARCH and asymmetric models and observes some stylized fact characteristic volatility of exchange rate time series.

\subsection{Source of Data}

\section{Methodology}

The time series data used in this analysis consists of daily data over the period June $1^{\text {st }}, 2000$ to July 26 , 2011 consisting of 4083 observations. Data have been obtained from daily trust newspaper, through the website [32].

The return on exchange rate is defined as:

$$
r_{t}=\log \left(\frac{e_{t}}{e_{t-1}}\right)
$$

Where $e_{t}$ mean dollar/naira exchange rate at time t and $e_{t-1}$ represent naira exchange rate at time $\mathrm{t}-1$. The $r_{t}$ of equation (1) will be used in observing the volatility of daily exchange rate in Nigeria.

\subsection{Stylized Facts about Volatility Model}

Here are some characteristics of common features of good volatility modeling on financial time series.

\section{Fat Tails}

Financial time series often exhibit leptokurtosis, meaning that the distribution of their returns is fattailed (i.e. the kurtosis exceed the kurtosis of a standard Gaussian distribution( see [21] or [13]). When compared to the normal distribution, the empirical distribution of financial time series exhibits a fourth moment (kurtosis) higher than the normal value of 3 and therefore has fatter tails. 


\section{Volatility Clustering}

Volatility clustering is often observed (i.e. large changes tend to be followed by large changes and small changes tend to be followed by small changes;[21] for early evidence). Another stylized fact is the socalled volatility clustering, which refers to the observation of large movements being followed by large movements and is an indication of persistence in past shocks.

\section{Leverage Effects}

First suggested by [3], this styled fact refers to the idea that price movements are negatively correlated with volatility. The distribution considered in ARCH and GARCH models is symmetric and fail to model the third stylized fact, namely the leverage effect. To solve this problem, many extensions to GARCH models have been proposed.

\section{Mean Reverting}

Volatility clustering implies that volatility comes and goes. Thus a period of high volatility will eventually give way to more normal volatility and similarly, a period of low volatility will be followed by a rise. Mean reversion in volatility is generally interpreted as meaning there is a normal level of volatility to which volatility will eventually return. Very long run forecasts of volatility should all converge to this same normal level of volatility, no matter when they are made. While most practitioners believe this is a characteristic of volatility, they might differ on the normal level of volatility and whether it is constant over all time and institutional changes.

\section{Persistence of Volatility}

Volatility persistence is a feature that many time series models are designed to capture. A GARCH model features an exponential decay in the autocorrelation of conditional variances. However, it has been noted that squared and absolute returns of financial assets typically have serial correlations that are slow to decay similar to those of an I(d) process. A shock in the volatility series seems to have very "long memory" and impact on future volatility over a long horizon. The Integrated GARCH (IGARCH) model of [10] captures this effect but a shock in this model impacts upon future volatility over an infinite horizon and the unconditional variance does not exist for this model. A further measure of persistence in a volatility model is the half life of volatility. This is defined as the time taken for the volatility to move half way back towards its unconditional mean following deviation from it. The forecast future of volatility then will depend upon information in today's information set such as today's returns. Volatility is said to be persistence if today's return has a large effect on the forecast variance many periods in the future.

\section{Asymmetric Effects}

A stylized fact of financial volatility is that bad news (negative shocks) tends to have a larger impact on volatility than good news (positive shocks). In other words, volatility tends to be higher in a falling market than in a rising market. Based on this conjecture, the asymmetric news impact on volatility is commonly referred to as the leverage effect ([9]).

\subsection{GARCH $(p, q)$ Model and its Properties}

In practice, it is often found that a large number of lags $\mathrm{p}$, and a large number of parameters, are required to obtain a good model fit of ARCH (p) model. To circumvent this problem [4] proposed the generalized ARCH or GARCH (p,q) model, with the following formulation:

$$
\begin{aligned}
& h_{t}=\alpha_{o}+\sum_{i=1}^{p} \alpha_{i} \varepsilon_{t-i}^{2}+\sum_{i=1}^{q} \beta_{i} h_{t-i} \\
& h_{t}=\alpha_{o}+\alpha_{1} \varepsilon_{t-1}^{2}+\ldots+\alpha_{p} \varepsilon_{t-p}^{2}+\beta_{1} h_{t-1}+\ldots+\beta_{q} h_{t-q}
\end{aligned}
$$

where,

$$
\begin{aligned}
& h_{t-i} \text { is the volatility at day } \mathrm{t}-\mathrm{i} \\
& \alpha_{o}>0 \\
& \alpha_{i} \geq 0 \text { for } i=1, \ldots, P \\
& \beta_{i} \geq 0 \text { for } i=1, \ldots, q \\
& \varepsilon_{t-i}^{2} \text { and } h_{t} \text { are as previously defined. }
\end{aligned}
$$


Under the GARCH (p, q) model, the conditional variance of $\varepsilon_{t}, h_{t}$, depends on the squared innovations in the previous p periods, and the conditional variance in the previous q periods. The GARCH models are adequate to obtain a good volatility model fit for financial time series. Rearranging the GARCH $(p, q)$ model by defining $u_{t} \equiv \varepsilon_{t}^{2}-h_{t}$, it follows that

$\varepsilon_{t}^{2}=\alpha_{o}+(\alpha(L)+\beta(L)) \varepsilon_{t}^{2}-\beta(L) u_{t}+u_{t}$

Where, $\mathrm{L}$ is a backshift operator and

$$
\begin{aligned}
& \alpha(L)=\alpha_{1} L+\ldots+\alpha_{p} L^{p} \\
& \beta(L)=\beta_{1} L+\ldots+\beta_{q} L^{q}
\end{aligned}
$$

which defines an ARMA (Max (q, p), q) model for $\varepsilon_{t}^{2}$. By standard argument, the model is covariance stationary if and only if all the roots of $(1-\alpha(L)-\beta(L))$ lie outside the unit circle. The ARMA representation in (3) allows for the use of time series techniques in the identification of the orders of $\mathrm{p}$ and $\mathrm{q}$.

\section{$\operatorname{GARCH}(1,1)$ Model}

$h_{t}=\alpha_{o}+\alpha_{1} \varepsilon_{t-1}^{2}+\beta_{1} h_{t-1}$

where,

$\beta_{1}$ Measures the extent to which a volatility shock today feed through into the next period's volatility. $\left(\alpha_{1}+\beta_{1}\right)$ Measures the rate at which this effect dies over time. $h_{t-1}$ is the volatility at day t-i.

\subsection{GARCH Model Extensions}

In most cases, the basic GARCH model provides a reasonably good model for analyzing financial time series and estimating conditional volatility. However, there are some aspects of the model, which can be improved so that it can better capture characteristics, and dynamics of a particular time series. Since bad news (negative shocks) tends to have a large impact on volatility than good news (positive shocks), hence here is need to talk about the GARCH extensions model and we have restricted our analysis to the more popular models of asymmetric volatility, Such as TGARCH, GJR-GARCH, and TS-GARCH.

TGARCH Model

Another GARCH Variant that is capable of modeling leverage effects is the threshold GARCH (TGARCH) model, which has the following form:

$h_{t}=\alpha_{o}+\sum_{i=1}^{p} \alpha_{i} \varepsilon_{t-i}^{2}+\sum_{i=1}^{p} \gamma_{i} S_{t-i} \varepsilon_{t-i}^{2}+\sum_{j=1}^{q} \beta_{j} h_{t-j}$

where,

$$
S_{t-i}=\left\{\begin{array}{l}
1 \text { if } \varepsilon_{t-i<0} \\
0 \text { if } \varepsilon_{t-i \geq 0}
\end{array}\right.
$$

$\gamma_{i}=$ leverage effects coefficient. (if $\gamma_{i}>0$ it indicates presence of leverage effect.) That is depending on whether $\varepsilon_{t-i}$ is above or below the threshold value of zero, $\varepsilon_{t-i}^{2}$ has different effects on conditional variance $h_{t}$ : when $\varepsilon_{t-i}$ is positive, the total effects are given by $\alpha_{i} \varepsilon_{t-i}^{2}$; when $\varepsilon_{t-i}$ is negative, the total effects are given by $\left(\alpha_{i}+\gamma_{i}\right) \varepsilon_{t-i}^{2}$. So one would expect $\gamma_{i}$ to be positive for bad news to have larger impacts.

\section{GJR-GARCH Model}

The GJR-GARCH model is another volatility model that allows asymmetric effects. This was introduced by [14]. The general specification of this model is of the form:

$$
\sigma_{t}^{2}=\omega+\sum_{i=1}^{q}\left(\alpha_{i} \varepsilon_{t-1}^{2}+\gamma_{i} S_{t-i}^{-} \varepsilon_{t-1}^{2}\right)+\sum_{j=1}^{p} \beta_{j} \sigma_{t-j}^{2}
$$


where $S_{t-i}^{-}$is a dummy variable which takes the value of 1 when $\gamma_{i}$ is negative and 0 when ${ }^{\gamma_{i}}$ it is positive. In this GJR-GARCH model, it is supposed that the impact of $\varepsilon_{t}^{2}$ on the conditional variance $\sigma_{t}^{2}$ differs when $\varepsilon_{t}$ is positive or negative. A nice aspect of the GJR model is that it is easy to test the null hypothesis of no leverage effects. In fact, $\gamma_{i}=\ldots=\gamma_{q}=0$ means that the news impact curve is symmetric, i.e. past negative shocks have the same impact on today's volatility as positive shocks.

\section{TS-GARCH Model}

The TS-GARCH model developed by [31] and later [30] is another popular model used to capture the information content in the thick tails, which is common in the return distribution of speculative prices. The specification of this model is based on standard deviations and is as follows:

$$
\left(h_{t}^{1 / 2}\right)=w+\sum_{i=1}^{p}\left(\phi\left|\varepsilon_{t-i}\right|\right)+\sum_{j=1}^{q} \beta_{j}\left(h_{t-j}^{1 / 2}\right)
$$

\subsection{Data Characteristics}

\section{Empirical Analysis}

There is clearly indication (Fig. 1) of upward trend in the data more specifically in the early periods of the study years, although in the middle of the study periods there is a fluctuation that results to more upward trend in the later periods.

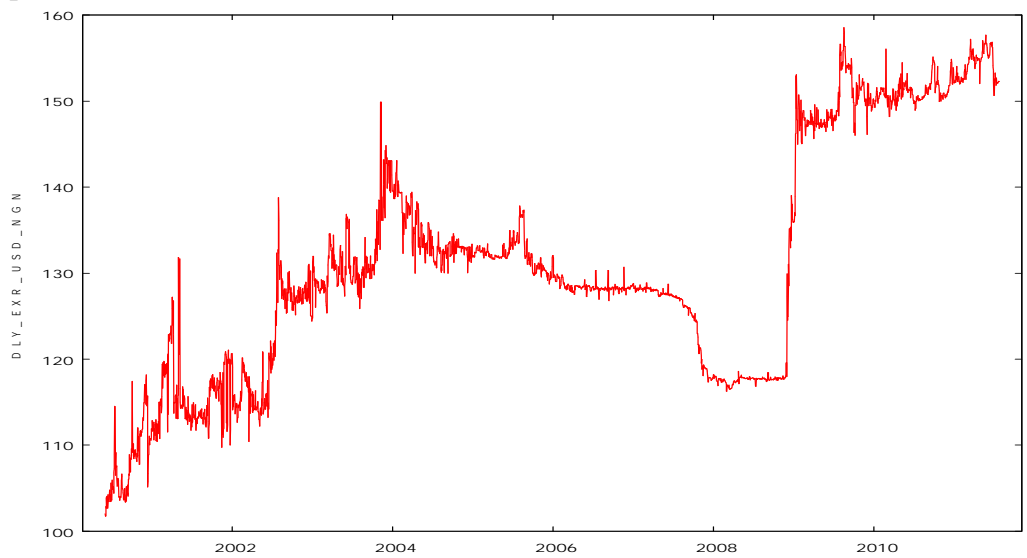

Fig 1: Time plot of Daily Exchange Rate of US Dollar /NG Naira

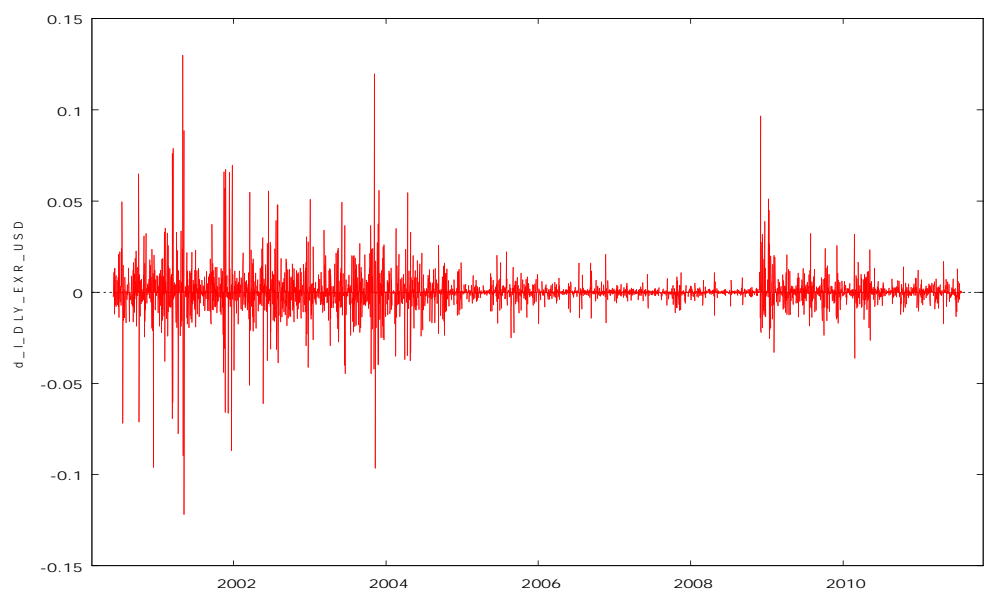

Fig. 2: First difference of Daily Exchange Rate of USD/NGN

Fig. 2 reveals that some periods are riskier than others. Also the risky times are scattered randomly and there is some degree of autocorrelation in the riskiness of financial returns. (i.e. large changes tend to be followed by 
large changes and small changes tend to be followed by small changes is volatility clustering ([21]) and is one of the stylized facts of volatility of financial time series. We also observed that the clustering of periods of volatility that is large movements followed by further large movements; the variance of exchange rate returns is not constant over time. This is an indication of shock persistence [7],which is another stylized fact of volatility of financial time series.

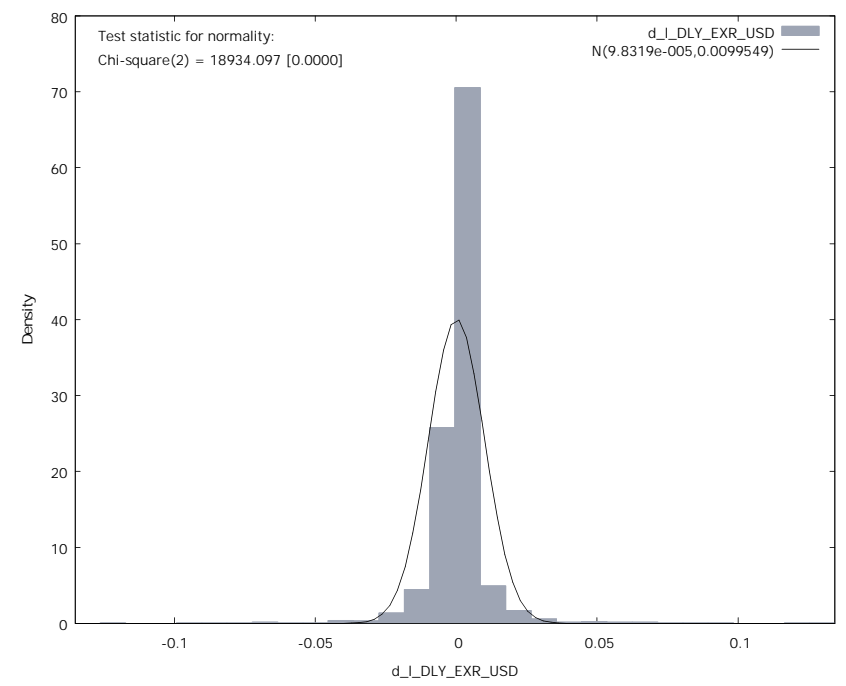

Fig 3: Frequency Distribution of Exchange rate Between US Dollar/ NG Naira

The Fig. 3 clearly shows that the error may not likely normally distribute, at the same time are farther apart. And they are not spread and its can result in to higher kurtosis (kurtosis greater than 3 of normal distribution) which is another characteristics. In the other hand, if the distribution is not normal, the skewness will be different from zero and the distribution is asymmetrical ( i.e negative skewness or leptokurtic). But are times, the leverage effect of financial time series result from asymmetrical effect produced from the skewness of the distribution. In this context, negative shock increase predictable volatility in asset markets more than positive. A shock which increases the volatility of the market, increase the risk of holding the currency [28].

\section{Unit Root Test for the Exchange Rate}

The ADF statistic test ([5]) the null hypothesis of unit root against the alternative of no unit root and the decision rule is to reject the null hypothesis when the value of the test statistic is less than the critical value. The KPSS statistic tests ([20]) the null hypothesis of stationarity against the alternative of non stationarity and the decision rule is to accept the null hypothesis when the value of the test statistic is less than the critical value. The results of the ADF and KPSS tests are in the Table below.

Table 1: Results of the Unit Root test for the Exchange Rate.

\begin{tabular}{|l|l|l|}
\hline Critical Values & ADF Test Statistics: $\mathbf{- 4 5 . 6 9 4 9}$ & KPSS Test Statistics: 0.0284 \\
\hline $1 \%$ & -3.96 & 0.216 \\
\hline $5 \%$ & -3.41 & 0.146 \\
\hline $10 \%$ & -2.57 & 0.119 \\
\hline
\end{tabular}

Table 1 the ADF test statistic is greater than all the critical values in absolute value so the hypothesis of nonstationarity is rejected. And for KPSS test statistic is less than the critical value hypothesis is accept.

\section{Testing for ARCH Effects}

We have shown that the series are stationary, our aims here is to test for the ARCH effects in the residuals of the exchange rate and to establish if the ARCH effects are due to structural breaks or not.

Table 2 Results of ARCH LM test, assuming without structural breaks

\begin{tabular}{|l|l|}
\hline Test Statistic & P-Value $\left(\right.$ chi $\left.^{\wedge} 2\right)$ \\
\hline 217.0407 & 0.0000 \\
\hline
\end{tabular}


Investigating Daily Naira/Dollar Exchange Rate Volatility: A Modeling using GARCH and

Table 3 Results of ARCH-LM Test for Structural Breaks

\begin{tabular}{|l|l|l|l|}
\hline & Sub period 1 & Sub period 2 & Sub period 3 \\
$01 / 06 / 2000-01 / 06 / 2003$ & $02 / 06 / 2003-31 / 12 / 2007$ & $01 / 01 / 2008-26 / 07 / 2011$ \\
\hline Test Statistic & 77.7535 & 22.6693 & 16.9394 \\
\hline P-Value chi`2) $^{\text {P }}$ & 0.0000 & 0.0000 & 0.0002 \\
\hline
\end{tabular}

From Table 2-3 result show that whether or not we assume structural breaks in exchange rate. There is evidence of ARCH effects for all the exchange rate across the groups and they can be modeled as conditional heteroscedastic model. The ARCH effects are not due to structural breaks as there are ARCH effects across the sub groups.

Table 4 Results of the portmanteau Test for Exchange Rate

\begin{tabular}{|l|l|l|}
\hline Test & Exchange rate & Square Exchange rate \\
\hline Ljung Box & 341.3525 & 882.4921 \\
\hline P-value & 0.0000 & 0.0000 \\
\hline
\end{tabular}

The null hypothesis of no autocorrelation cannot be accepted in all cases we conclude that there are strong autocorrelation in the squared returns.

\section{Jarque-Bera Test for Normality.}

We examine the characteristics of the unconditional distribution of the exchange rate. This will enable us to explore and explain some stylized facts embedded in the financial time series. Jarque Bera normality test is used to demonstrate this and the results are given below

Table 5: Jarque - Bera Test for Normality

\begin{tabular}{|l|l|}
\hline Mean & 0.000098319 \\
\hline Median & 0.00000 \\
\hline Minimum & -0.12180 \\
\hline Maximum & 0.12991 \\
\hline Std.dev. & 0.009954 \\
\hline Skewness & 0.3795 \\
\hline Kurtosis & 42.9911 \\
\hline Jakue Bera Test & 271377 \\
\hline P- value & 0.0000 \\
\hline
\end{tabular}

Table 5 the results indicate the positive mean of daily exchange rate between USD/NGN, and standard deviation appear to be higher which follow the introduction of market determine exchange rate. The skewness is positively skews relative to the normal distribution ( 0 for the normal distribution). This is an indication of a non symmetric series. The kurtosis is very much larger than 3, the kurtosis for a normal distribution. Skewness indicates non-normality, while relatively large kurtosis suggests that distribution of the exchange rate return series is leptokurtic (i.e. exhibit fat tail), Jarkue-Bera normality test statistics, indicating that neither return series has normal distribution.

\subsection{Model Identification}

The particular optimization routine of the log-likelihood function shows that ARCH (5) and GARCH $(1,1)$ are the optimal model for the returns. To avoid the problem of number of terms sufficiency and for parsimony for $\operatorname{ARCH}(5)$ with high order, we implement $\operatorname{GARCH}(1,1)$ as its optimality among GARCH $(\mathrm{p}, \mathrm{q})$ models.

\subsection{Model Checking}

Table 8: Results for no Remaining ARCH Effects in Residual

\begin{tabular}{|l|l|}
\hline F- Test & P-value \\
\hline 0.00308 & 0.9511 \\
\hline
\end{tabular}

From the Table 8 above, the null hypothesis that there is no ARCH effects remaining at every lag is accepted since all the p- values are greater than 0.05 therefore the models are adequate.

Table 9: Results of ARCH LM Test for GARCH $(1,1)$ Residuals

\begin{tabular}{|l|l|l|}
\hline \multicolumn{1}{|c|}{ Lag } & Test Statistics & P-value \\
\hline 1 & 1.2885 & 0.2568 \\
\hline 2 & 1.4737 & 0.4786 \\
\hline 3 & 1.5147 & 0.6789 \\
\hline 4 & 1.5777 & 0.8128 \\
\hline
\end{tabular}


The null hypothesis of no ARCH effects should be accepted as in Table 9 and the conclusion is that the models are adequate.

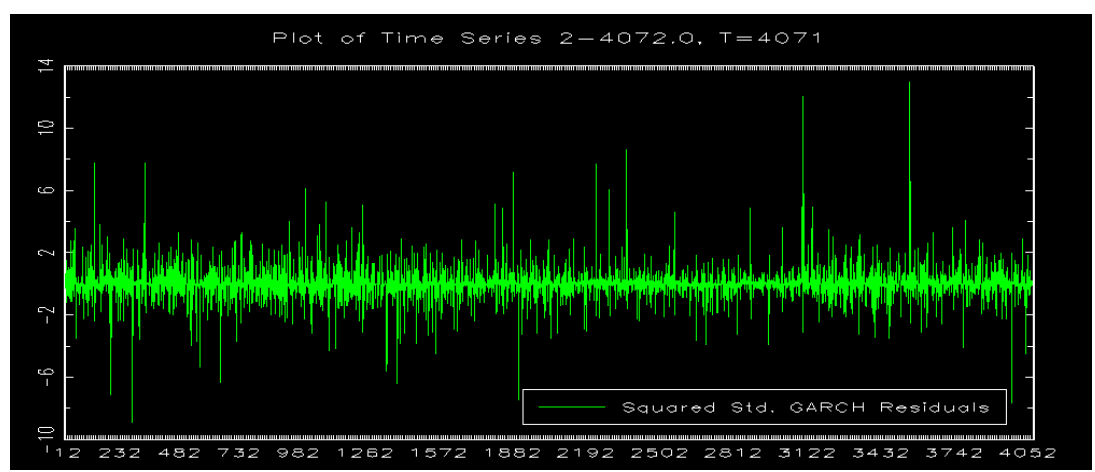

Fig 7: Estimated conditional volatility of the exchange rate using $\mathrm{GARCH}(1,1)$

Fig. 7 shows that the time series reverts quite quickly to its mean and is uniformly distributed.

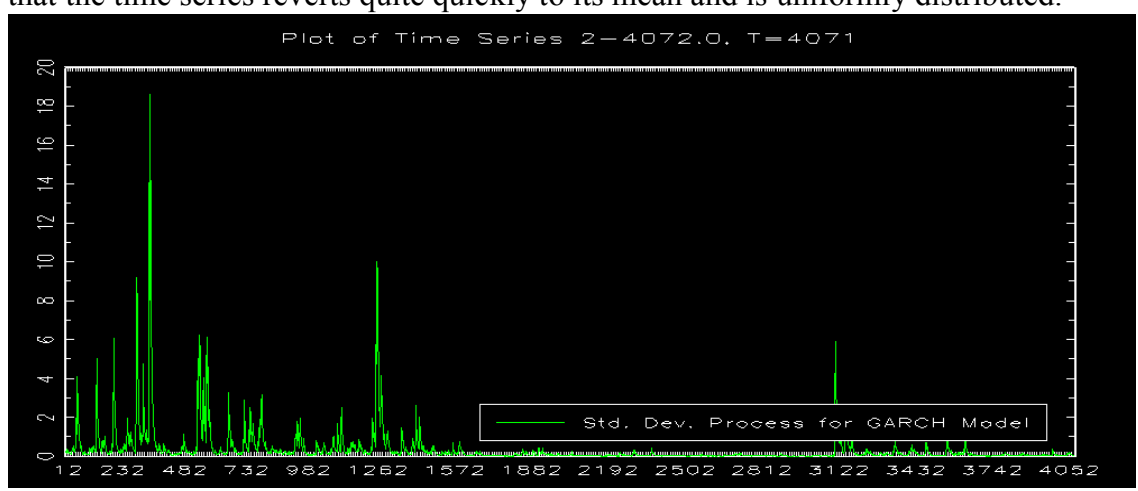

Fig. 8: Estimated conditional volatility of the exchange rate using $\operatorname{GARCH}(1,1)$

Fig 8 clearly Show that, the estimated volatility function is skewed and thus reveals asymmetry as display a Ushaped structure. We can observe that downward movements in the daily dollar/naira exchange rate return are follows by higher volatilities than upward movements of the same size of changes. That is the abnormal return will have more volatility especially for the negative abnormal.

\subsection{Analysis of some Volatility Models}

Table 10: Parameter Estimates of GARCH models for the Period, June 2000 - July 2011

\begin{tabular}{|l|l|l|l|l|}
\hline & GARCH(1,1) & GJR-GARCH(1,1) & TGARCH(1,1) & TS-GARCH(1,1) \\
\hline$\alpha_{o}$ & $1.4838 e-08$ & $3.1138 e-07$ & $2.6358 e-07$ & $1.8672 e-07$ \\
& $(3.2433 e-07)$ & $(1.8694 e-06)$ & $(3.1639 e-07)$ & $(3.7609 e-07)$ \\
$\alpha_{1}$ & 0.5576 & 1.1485 & 0.2427 & 0.2725 \\
& $(1.2791)$ & $(8.7710)$ & $(0.1568)$ & $(0.1919)$ \\
$\gamma_{1}$ & & -0.3312 & -0.7970 & \\
$\beta_{1}$ & $(6.5431)$ & $(0.3044)$ & 0.9647 \\
& & 0.9732 & 0.9681 & $(0.0149)$ \\
Persistence & 0.9755 & $(0.0159)$ & $0.1187)$ & 1.2372 \\
\hline AIC & $(0.0114)$ & 1.9561 & 0.81238 & \\
\hline SI C & 1.5331 & & & -33370.04158 \\
\hline LL & -33337.26213 & -33347.01232 & -33392.98844 & -33338.48336 \\
\hline
\end{tabular}


From Table 10 show that $\alpha_{1}$ coefficient is not statistically significant in the GARCH and GJR-GARCH models but significant at the $5 \%$ level in TGARCH and TS-GARCH models. This appears to show the presence of volatility clustering in TGARCH and TS-GARCH models. Conditional volatility for these models tends to rise (fall) when the absolute value of the standardized residuals is large (smaller).

The coefficient of $\beta_{1}$ (a determinant of the degree of persistence) are statistically significant in all the models. The sum of $\alpha_{1}$ and $\beta_{1}$ in the GARCH model exceed 1. This appears to show that shocks to volatility are very high. The GJR-GARCH models that is $\alpha_{1} \beta_{1}+\left(\gamma_{1} / 2\right)$ exceed 1 . This also appears to show that shocks to volatility are very high and the variances are not stationary under The GJR-GARCH model. But under TGARCH model $\alpha_{1}+\beta_{1}+\left({ }^{\gamma_{1}} / 2\right)$ is less than 1 showing persistent volatility in the TGARCH model. The sum of $\alpha_{1}$ and $\beta_{1}$ in the TS-GARCH model exceeds 1 . This appears to show that shocks to volatility are very high and will remain forever as the variances are not stationary under TS-GARCH model. So however, in sum, the

Nigeria exchange rate market is characterized by high volatility persistence. The $\gamma_{1}$ coefficient is asymmetry and leverage effects, are negative and statistically significant at the $5 \%$ level in the GJR-GARCH and TGARCH models. However, leverage effect will only exist $\gamma_{1>0}$ in the GJR-GARCH and TGARCH models and negative values of $\gamma_{1}$ in the GJR-GARCH and TGARCH models, the hypothesis of leverage effect is rejected for all models but asymmetry effect is accepted for the GJR-GARCH and TGARCH models. The results from the asymmetry models rejected the hypothesis of leverage effect. That is the GJR-GARCH and TGARCH models show the existence of statistically significant asymmetry effect. The TS-GARCH and TGARCH models are found to be the best models.

\subsection{Conclusion}

\section{Conclusion And Recommendation}

We use daily Exchange rate volatility model between United States dollar and Nigeria naira for the period $1^{\text {st }}$ June, 2000 to $26^{\text {th }}$ July, 2011 to modeled the volatility of daily exchange rate with different types of GARCH family models and to observe some stylize fact characteristics volatility of exchange rate, such as persistence, volatility clustering, leverage effect etc. The results from all the models show that volatility is persistent (i.e. exceed 1) indicating GARCH $(1,1)$, GJR-GARCH $(1,1)$, and TS-GARCH $(1,1)$ models variances are not stationary but for TGARCH $(1,1)$ model (i.e. below 1$)$ indicating the variance is stationary. The results from all the asymmetry models rejected the hypothesis of leverage effect. The GJR-GARCH $(1,1)$ and TGARCH $(1,1)$ models show the existence of statistically significant asymmetry effect. The TGARCH $(1$, 1) and TS-GARCH models are found to be the best models because they have maximum likelihood and lower information criteria.

\subsection{Recommendation}

From the results of the analysis, TGARCH $(1,1)$ and TS-GARCH $(1,1)$ models are recommended to be the fitted models because they have all the parameters of the variance being significant and they have maximum likelihood, lower Akaike information criteria and Schwarz information criteria. The research can serve as a step to observe the volatility modeling of the Nigeria exchange rate. We recommend the use of these models in capturing the effect and predictions of the volatility behavior of Nigeria exchange rate.

\section{References}

[1] Adedayo A. A., Olaoluwa S.Y. and Oluwadare O. O. (2013) Estimation of GARCH Models for Nigerian Exchange Rates under Non-Gaussian Innovations. Journal of Economics and Sustainable Development, Vol. 4(3): 88-97

[2] Awogbemi Clement and Alagbe Samuel (2011) Empirical Modeling of Nigerian Exchange Rate Volatility. Mathematical Theory and Modeling, Vol.1(3): 8-15

[3] Black, F. (1976) Studies in Stock Price Volatility Changes, Proceedings of the 1976 Business Meeting of the Business and Economics Statistics section, published by American Statistical Association.

[4] Bollerslev, T. (1986) Generalised Autoregressive Conditional Heteroskedasticity, Journal of Econometrics. 51: 307-327.

[5] Dickey, D.A. and Fuller, W. A. (1979) Estimators for Autoregressive Time series with a unit root, Journal of the American Statistical Association. 74: 427 - 432

[6] Ding, Z., R.F. Engle and C.W.J. Granger.(1993). "Long Memory Properties of Stock dynamics and Control. Econometric Reviews. 6: 318 - 334 .

[7] Engle R. F. \& A. J. Patton, (2001). "What good is a volatility model?," Quantitative Finance, Taylor \& Francis Journals, vol. 1(2), pages $237-245$

[8] Engle, R. F. (1982). Autoregressive Conditional Heteroscedasticity with Estimates of the Variance of United Kingdom Inflation. Econometrica. 50(4): 987-1008. 
[9] Engle, R.F. (2001) Financial Econometrics- A New Discipline with New Methods, Journal of Econometrics. $100: 53$ - 56.

[10] Engle, R.F. and Bollerslev, T. (1986) Modelling the persistence of conditional variances, Econometric Reviews. 5(1-50): 81-87.

[11] Engle, R. F., D M. Lilien, and R P. Robins. (1987).Estimating Time Varying Risk Premia in the Term Structure: The ARCH-M Model, Econometrica. 55: 391-407.

[12] Esquivel, G. and Larrain, F. B.(2002), The Impact of G-3 Exchange Rate Volatility on Developing Countries G-24 Discussion Paper Series No. 16, United Nations Conference on Trade and Development, United Nations, New York and Geneva, January 2002.

[13] Fama, Eugene F., (1965) The Behavior of Stock - Market Prices, journal of Business. 1(38): $34-105$

[14] Glosten, L, Jagannathan, R and Runkle, D. (1993), On the relationship between the Expected Value and the Volatility of the Nominal Excess Return on Stocks, Journal of Finance. 48:1779-1802.

[15] Hamadu, Dallah and Ibiwoye, Ade (2010), Modelling and Forecasting the Volatility of the Daily Returns of Nigerian Insurance Stocks, International Business Research. 3(2): 2010, 106-116.

[16] Hsieh, D.A. (1989). Modeling heteroscedasticity in daily foreign-exchange rates. Journal of Business \& Economic Statistics, 7 , 307-317. http://dx.doi.org/10.2307/1391528

[17] Husain Fayyaz and Jalil Abdul (2007), Pakistan, "Effectiveness of Foreign Exchange Intervention: Evidence from Pakistan", SBP Research Bulletin, Vol. 3, Number 2, 2007.

[18] Jarque, C. M. and Bera, A. K. (1987) A test for Normility of Observations and Regression Residuals, International Statistical Review. 2: 163-172.

[19] Kasman, S., Vardar, G.and Tunc, G. (2011). "The impact of interest rate and exchange rate volatility on banks $\square$ stock returns and volatility: Evidence from Turkey", Economic Modelling, 28:1328-1334

[20] Kwiatkowski, D., Phillips, P. C. B., Schmidt, P. and Shin Y. (1992) Testing the Null of Stationarity against the alternative of Unit root: How sure are we that the economic time series have a unit root, Journal of Econometrics. 54: 159- 178 .

[21] Mandelbrot, B. (1963) The Variation of Certain Speculative Prices, Journal of Business. 4/36: 394 - 419

[22] McKenzie, M.D. (1997) ARCH Modeling of Australian Bilateral Exchange Rate Data Applied Financial Economics. $7: 147$ - 164.

[23] Meese, R.A. and Rose, A.K. (1991) An Empirical Assessment of Nonlinearities in Models of Exchange Rate Determination. Review of Economic Studies. (58) pp. 6032

[24] Mundaca B.G. (1991). The volatility of the Norwegian currency basket. Scand. J. Econ. 93(1): 53-73.

[25] Nelson, Daniel B. (1991) Conditional Heteroskedasticity in Asset Returns: A New Approach. Econometrica. 59(2): 347-370.

[26] Olowe, Ayodeji R (2009). Modeling Naira/Dollar Exchange Rate Volatility: Application of GARCH and Asymmetric Models. International Review of Business Research Papers 5(3): 377-398.

[27] Robinson, J. and W. Robinson (1998), "Monetary Policy and the Jamaican Economy: A Study of the Transmission Mechanism," Bank of Jamaica Working Paper.

[28] Robinson, W. and Longmore, R. (2004), Modelling and Forecasting Exchange Rate Dynasmics in Jamaica: An Application of Asymmetry Volatility Models. Working Paper WP 2004/03

[29] Sanusi, J. O. (2004) "Exchange rate mechanism: The Current Nigerian Experience", Being a paper delivered at the laundries of the Nigerian - British Chamber of Commerce, Feb. 24, 2004.

[30] Schwert, G.W. (1990). "Stock Market Volatility," Financial Analyst Journal, May-June, Vol. 46, $23-34$.

[31] Taylor, S. (1986). Modelling Financial Time Series John Wiley \& Sons, Great Britain.

[32] www.http://fxtop.com/en/historates.php-cached-Block all, (2011).

[33] Yoon, S. and K. S. Lee (2008), The Volatility and Asymmetry of Won/Dollar Exchange Rate. Journal of Social Sciences. 4 (1): 7-9.

[34] Zakoïan, J. M. (1994). Threshold Heteroskedastic Models, Journal of Economic Dynamics and control. 18: $931-944$. 